\title{
Intracranial Hodgkin's disease shown by radioisotope scan
}

\author{
S. CURRIE AND G. W. H. JARDINE
}

\author{
From the Departments of Neurology and Radiotherapy, The London Hospital, London
}

Verified intracranial deposits of Hodgkin's disease are rare. Thus there was only one among 125 cases reported by John and Nabarro (1955). In the monograph by Williams, Diamond, Craver, and Parsons (1959) there were four among 1,992 cases. Todd (1967) reported two among 1,339 cases. The deposits are usually subdural, intracerebral metastases being exceptional. This rarity contrasts with the incidence of spinal extradural deposits, around $5 \%$ in most series (Goldman, 1940; Smith and Stenstrom, 1948; Verity, 1968; Currie and Henson, 1969); the absence of a true intracranial extradural space may be a factor, as pointed out for lymphosarcoma by Jernstrom, Crockett, and Bachhuber (1966). In only two of the cases of subdural metastasis recorded in the literature has intravenous gammaencephalography been carried out (Gaelen and Levitan, 1967; Verity, 1968), in each as an adjunct to contrast studies (arteriography and pneumography). Its use is described in a further case which presented with epilepsy and was confirmed at necropsy. Its place in the investigation and management of similar cases is discussed; this is pertinent as, firstly, the rarity means that a coincidental lesion needs exclusion and, secondly, the relatively benign nature of most deposits, which are solitary and compress rather than invade brain, makes their demonstration more than an academic exercise.

\section{CASE REPORT}

The patient (P. McD. London Hospital No. 165416), a 21-year-old woman, first attended the Radiotherapy Department in October 1967 with a history of abdominal pain for one year and of sweating and sciatica for three months. On examination there was cervical adenopathy. Radiographs of the chest showed a mediastinal mass. Supraclavicular lymph node biopsy revealed diffuse fibrous Hodgkin's tissue. A course of $220 \mathrm{kV}$ irradiation was given to the mediastinum, neck, and axillae with a tumour dose of $2,500 \mathrm{r}$ in 15 treatments over 20 days. In April 1968 collapse of the left lung occurred due to obstruction of the left main bronchus; a further course of irradiation relieved her dyspnoea. During an admission in May 1968, with dysphagia due to pharyngeal moniliasis, the patient suffered an episode of focal sensory epilepsy in which tingling occurred in the left hand spreading to the whole limb within seconds; for 10 minutes subsequently there was numbness and for 24 hours, weakness of this limb. In June 1968 a left-sided focal attack occurred, this time motor, affecting the face then upper limb with a Jacksonian march, followed by loss of consciousness. An electroencephalogram suggested a right fronto-parietal lesion. A gamma-encephalogram (GEG) was performed using $10 \mathrm{mC}$ Technetium-99m with automatic continuous brain scanning; this showed a superficial circumscribed fronto-parietal lesion, approximately $3 \mathrm{~cm}$ in diameter (Figs. 1a and b). The patient was given phenobarbitone and had no further attacks. In view of the widespread disease, she was treated by antimitotic drugs (procarbazine, cyclophosphamide), but her respiratory condition continued to deteriorate and she died in August 1968.

Necropsy (No. 229/68) showed involvement of the mediastinum, lungs, spleen and bone marrow as well as of lymph nodes. There was a $3 \mathrm{~cm}$ subdural deposit resulting in a depression in the right parietal region of the brain (Figs. 2 and 3); macroscopically it resembled a meningioma. Neither bone nor brain was invaded. Histological examination of this deposit showed diffuse fibrous Hodgkin's tissue, as in the earlier biopsy, with small numbers of Reed-Sternberg cells and scanty lymphocytes (Fig. 4).

\section{DISCUSSION}

The published reports of intracranial deposits of Hodgkin's disease have used the classification of Jackson and Parker (1944). This comprises paragranuloma (which does not involve the nervous system), granuloma (producing intracranial metastases in less than $0.5 \%$ of cases), and sarcoma (which may occur as a primary mesenchymal brain tumour). While the value of this classification is limited by most cases falling into the granuloma group, the more detailed one of Lukes and Butler (1966) is often hard to apply, due to variation within a single lesion. The histology in our case is to some extent non-specific, being found terminally in many. Regardless of which classification is used, intracranial metastasis is rare, the present case being the only verified one in 210 cases attending the London Hospital over a period of 10 years (a further case had 

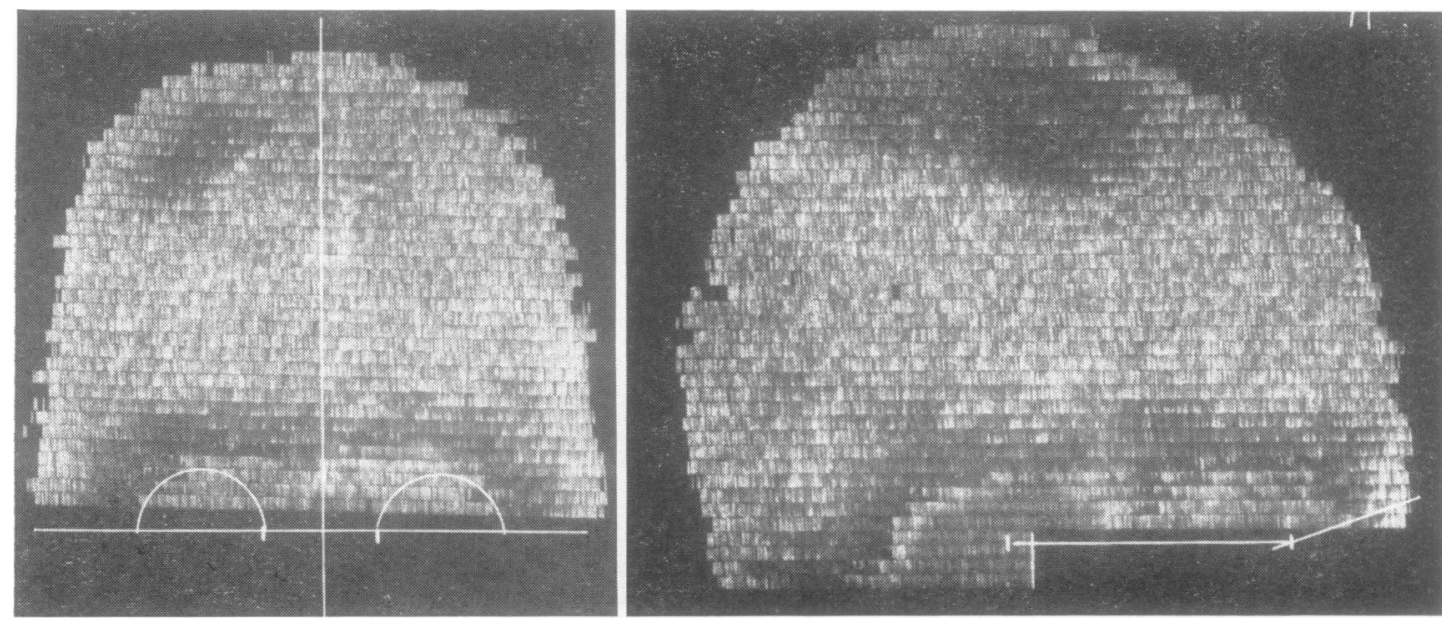

FIG. 1. (a) Negative of Color-scan; A/P. (b) Negative of Color-scan; R. lateral

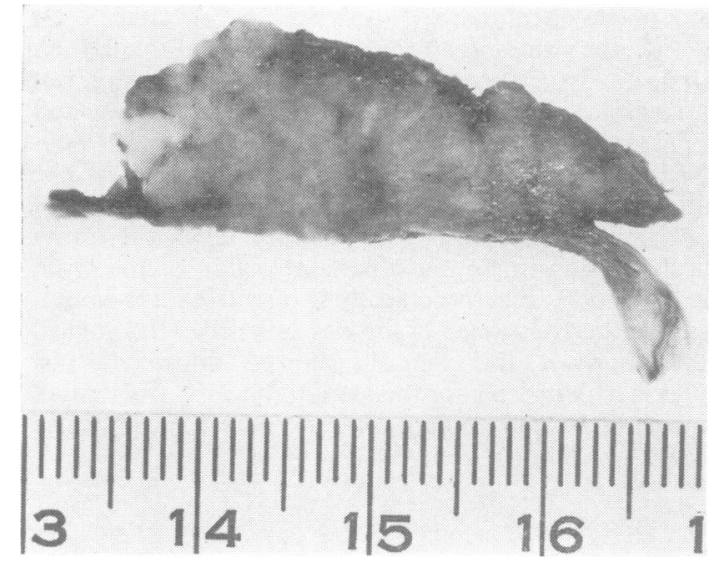

FIG. 2. Subdural deposit.

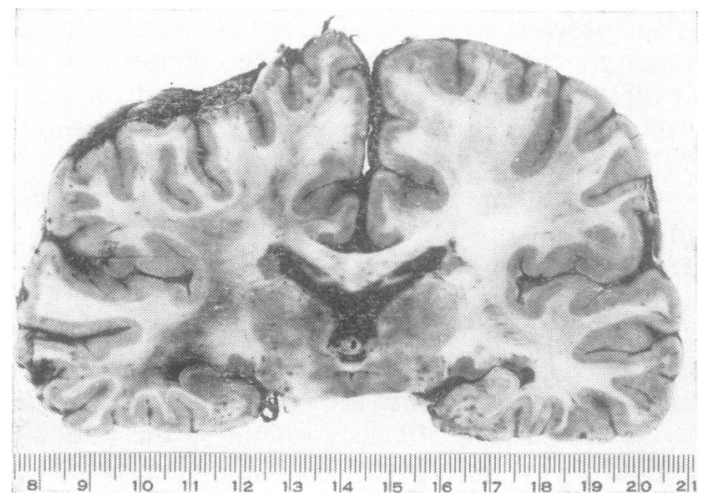

FIG. 3. Coronal section of brain showing depression. an asymptomatic deposit); this is in accord with the published series including the recent one of Todf $\omega$ (1967) who found two cases in 1,339 seen i i $\vec{\omega}$ Manchester during 18 years. Our case illustrates we을 the characteristic subdural deposit with compression but not invasion of underlying brain. Fein and Newill (1954) recorded a case in which obliteration of the subdural space and invasion of the brain dia $\stackrel{\oplus}{\oplus}$ occur. Buckley and Warwick (1968) described a cas: $\vec{\varphi}$ in which a subdural deposit was said to involve brain; whether this meant actual invasion is uncertain from their report. In their review of the literature, Ljungdahl, Strang, and Tovi (1965) suggested that intracerebral and those subdural $\overline{0}$ deposits not attached to bone might be haematogenous, implying that non-viability of most tumour $\unrhd$ emboli might explain both the rarity of deposits and $\vec{\circ}$ the occurrence of episodes without necropsy findings. $\exists$ The clinical picture of metastasis is unlike that of the progressive multifocal leucoencephalopathy which may accompany the reticuloses and which is probably due to viral action allowed by reduced immunological reactivity (Richardson, 1961; Howatson, $\dot{0}$ Nagai, and Zu Rhein, 1965); in this mental symptoms with cortical, brain-stem and cerebellar signs occur. $\delta$ Winkelman and Moore (1941) described a complex case with apparent intracerebral as well as subdural 응 Hodgkin's disease but their illustrations are of leucoencephalopathy, as pointed out by Aström, Mancall, and Richardson (1958).

The uptake by tissues of radioactive isotopes is $\mathscr{N}$ dependent on factors such as vascularity and $N$ permeability, the latter being the more obscure in tumours, with possibly an active cellular component 0 (Planiol, 1966). The gamma emitter Technetium-

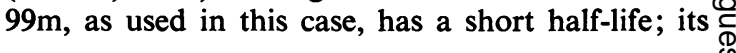




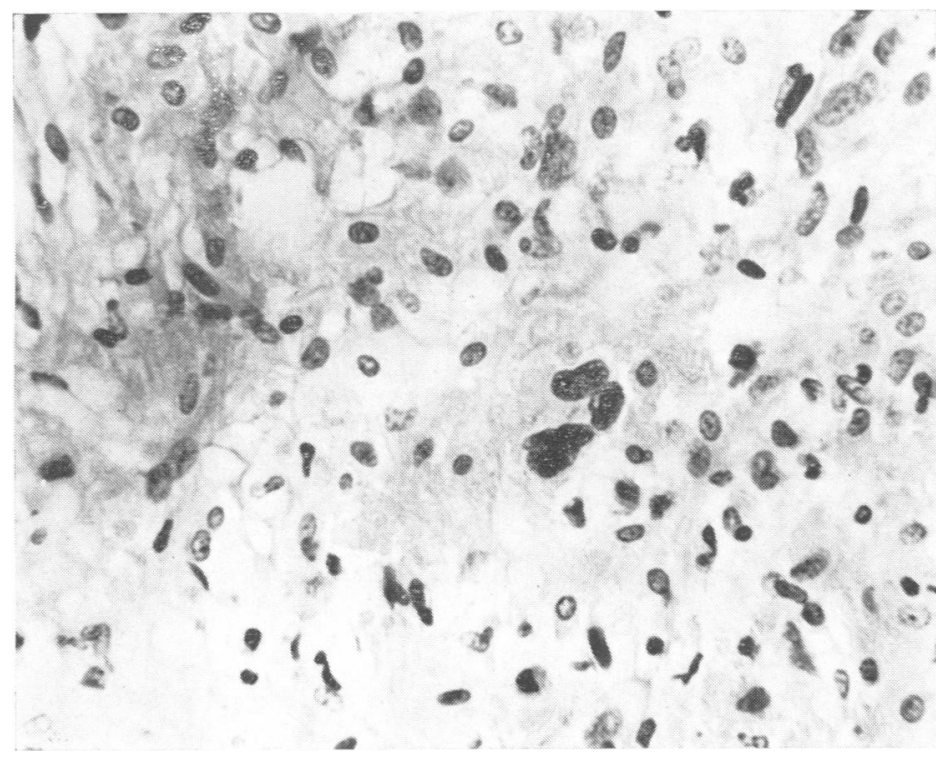

FIG. 4. Microscopy of subdural deposit. $H \& E \times 405$.

tumour concentration and the ratios of this to those in blood and brain allow well-defined pictures for an acceptable dose of radiation and examination time. Scanning can give only indirect help towards histological diagnosis, as Bull and Marryat stated (1965), except when multiple lesions indicate metastases; the technique of contact counting in Planiol's hands gives more accurate information. As well as obviating the need for contrast radiography in some cases, the GEG may be complementary to angiography in showing the extent of a tumour.

There should be no fatalistic preconceptions about the management of a patient with a reticulosis in whom intracranial tumour is suspected; this applies to malignant disease as a whole but needs stressing in a condition in which the course is unpredictable and intracranial metastasis exceptional. The tumour in one case of Todd's (1967) proved to be a coincidental meningioma. The unique case of Ljungdahl et al. (1965) of solitary intracerebral metastasis occurred in a woman whose Hodgkin's disease was otherwise in remission; the patient remained well three years after operation and radiotherapy. Gaelen and Levitan (1967) reported the removal of a subdural mass, shown by GEG and contrast radiography; the patient was alive nine months later. A case described by Verity (1968) also had contrast studies after a positive GEG and remained well over a year after operation. In each case there had been a history of progressive focal sensory disturbance for some months. Thus surgery with radiotherapy should be considered rather than radiotherapy alone on a presumptive diagnosis, even though the latter course may result in improvement, as reported by Hunt, Bouroncle, and Meagher (1959). In the present case, we would certainly have proceeded to angiography with a view to exploration had the general condition of the patient warranted this, the more so on account of the similarity of the deposit to a meningioma, symptomatically and on GEG-and, ultimately, on direct inspection.

\section{SUMMARY}

A case of Hodgkin's disease is described in which a subdural deposit presented with epilepsy, was demonstrated by gamma-encephalography, and confirmed at necropsy. The place of radiosotope studies in the management of similar cases is discussed.

Our thanks are due to Dr. H. F. Hope-Stone for permission to publish the case, Professor $H$. Urich for the photographs of the pathology, and the Physics Department for those of the GEG. This work was supported by the British Empire Cancer Campaign through the Neuropathological Research Unit of The London Hospital Medical College; we thank the Director, Dr. R. A. Henson, for this and for his advice.

\section{REFERENCES}

Aström, K. E., Mancall, E. L., and Richardson, E. P., Jr. (1958). Progressive multifocal leukoencephalopathy. A hitherto unrecognized complication of chronic lymphatic leukaemia and Hodgkin's disease. Brain, 81, 93-111.

Buckley, T. F., and Warwick, F. (1968). Surgical management of intracranial Hodgkin's disease. J. Neurol. Neurosurg. Psychiat., 31, 612-615. 
Bull, J. W. D., and Marryat, J. (1965). Isotope encephalography: experience with 100 cases. Brit. med. J., 1, 474-480.

Currie, S., and Henson, R. A. (1969). Neurological complications of the reticuloses. (In preparation).

Fein, S. B., and Newill, V. A. (1954). Cerebral Hodgkin's disease. Case report of Hodgkin's granuloma with cerebral invasion. Amer. J. med., 17, 291-294.

Gaelen, L. H., and Levitan, S. (1967). Solitary intracranial metastasis by Hodgkin's disease. Arch. intern. Med., 120, 740-745.

Goldman, L. B. (1940). Hodgkin's disease: an analysis of 212 cases. J. Amer. Med. Ass., 114, 1611-1616.

Howatson, A. F., Nagai, M., and Zu Rhein, G. M. (1965). Polyomalike virions in human demyelinating brain disease. Canad. med. Ass. J., 93, 379-386.

Hunt, W. E., Bouroncle, B. A., and Meagher, J. N. (1959). Neurologic complications of leukemias and lymphomas. J. Neurosurg., 16, 135-151.

Jackson, H., and Parker, F. (1944). Hodgkin's disease. II. Pathology. New Engl. J. Med., 231, 35-44.

Jernstrom, P., Crockett, H. G., and Bachhuber, R. G. (1966). Primary lymphosarcoma of cerebral meninges. J. Neurosurg., 24, 679-683.

John, H. T., and Nabarro, J. D. N. (1955). Intracranial manifestations of malignant lymphoma. Brit. J. Cancer, 9, 386-400.
Ljungdahl, I., Strang, R. R., and Tovi, D. (1965). Intracerebral Hodgkin's granuloma. Report of a case and review of the literature. Neurochirurgia (Stuttg.), 8, 113-118.

Lukes, R. J., and Butler, J. J. (1966). The pathology and nomenclature of Hodgkin's disease. Cancer Res., 26, 1063-1083.

Planiol, Th. (1966). Some aspects of brain-investigation by means of radio-isotopes. J. Neurol. Sci., 3, 539-564.

Richardson, E. P., Jr. (1961). Progressive multifocal leukoencephalopathy. New Engl. J. Med., 265, 815-823.

Smith, M. J., and Stenstrom, K. W. (1948). Compression of the spinal cord caused by Hodgkin's disease. Case reports and treatment. Radiology, 51, 77-84.

Todd, I. D. H. (1967). Intracranial lesions in Hodgkin's disease. Proc. roy. Soc. Med., 60, 734-736.

Verity, G. L. (1968). Neurologic manifestations and complications of lymphoma. Radiol. Clin. N. Amer., 6, 97-109.

Williams, H. M., Diamond, H. D., Craver, L. F., and Parsons, $\mathbf{H}$ (1959). Neurological Complications of Lymphomas and Leukemias. Thomas: Springfield, Illinois.

Winkelman, N. W., and Moore, M. T. (1941). Lymphogranulomatosis (Hodgkin's disease) of the nervous system. Arch. Neurol. Psychiat. (Chic.), 45, 304-318. 